\title{
O comportamento do consumidor de infoproduto
}

\author{
The infoproduct consumer behavior \\ El comportamiento del consumidor de infoproductos
}

Recebido: 11/02/2021 | Revisado: 16/02/2021 | Aceito: 24/02/2021 | Publicado: 02/03/2021

\author{
Ana Cássia Costa \\ ORCID: https://orcid.org/0000-0003-2261-2596 \\ Universidade Federal do Tocantins, Brasil \\ E-mail: anacassia.jor@gmail.com \\ Monique de Almeida Silva \\ ORCID: https://orcid.org/0000-0001-8234-7785 \\ Universidade Federal do Tocantins, Brasil \\ E-mail: moniquesjor@gmail.com
}

\begin{abstract}
Resumo
O comportamento do consumidor moderno se modifica de forma acelerada desde o boom da internet nos anos 2000 . Se naquela época já se anunciava a mudança de toda uma cultura da humanidade com o advento da web, com as redes sociais esse consumidor ficou cada vez mais ativo no processo e consciente de seu poder. O objetivo desse trabalho é analisar o comportamento desse consumidor de produtos digitais e para isso, utilizou-se de pesquisa bibliográfica e documental sobre o assunto. Esse é um tema em constante transformação e consequentemente, ainda há muito que se observar, pois a tecnologia também está em constante evolução. O que se pode observar a partir da literatura sobre o assunto, bem como a pesquisa documental, é que o consumidor tradicional mudou seu comportamento e tenta se adaptar ao consumo digital dada a gama de ofertas que esse novo formato oferece. Do outro lado, o mercado evolui para atender as necessidades cada vez mais exigentes do consumidor.
\end{abstract}

Palavras-chave: Infoproduto; Produto digital; Marketing.

\begin{abstract}
The modern consumer behavior has been changing quickly since the internet boom in the 2000s. If at that time the change of a whole culture of humanity was already announced with the advent of the web, with social networks this consumer has become even more active in the process and aware of its power. The objective of this work is to analyze the behavior of this consumer of digital products and for that, we used bibliographical and documentary research on the subject. This is a subject in constant transformation and, consequently, there is still much to be observed, as technology is also constantly evolving. What can be seen from the literature on the subject, as well as documentary research, is that the traditional consumer has changed his behavior and tries to adapt to digital consumption given the range of offers that this new format offers. On the other hand, the market evolves to meet the increasingly demanding needs of the consumer.
\end{abstract}

Keywords: Infoproduct; Digital product; Marketing.

\section{Resumen}

El comportamiento del consumidor moderno ha ido cambiando rápidamente desde el boom de Internet en la década de 2000. Si en ese momento el cambio de toda una cultura de la humanidad ya se anunció con la llegada de la web, con las redes sociales este consumidor se ha vuelto cada vez más activo en el proceso y consciente de su poder. El objetivo de este trabajo es analizar el comportamiento de este consumidor de productos digitales y para ello se utilizó la investigación bibliográfica y documental sobre el tema. Este es un tema en constante transformación y, en consecuencia, aún queda mucho por observar, ya que la tecnología también está en constante evolución. Lo que se desprende de la literatura sobre el tema, así como de la investigación documental, es que el consumidor tradicional ha cambiado de comportamiento e intenta adaptarse al consumo digital dada la gama de ofertas que ofrece este nuevo formato. Por otro lado, el mercado evoluciona para satisfacer las necesidades cada vez más exigentes del consumidor. Palabras clave: Infoproducto; Producto digital; Márketing.

\section{Introdução}

O produto não é mais um objeto exclusivo das prateleiras, ele é digital. O avanço da tecnologia mudou o mundo e continua a cada dia mudando o comportamento do indivíduo frente às inúmeras possibilidades de se comprar e vender pela internet. Dados do Mapa da Inclusão Digital (Neri, 2012) afirmam que o Brasil, naquela época, já estava acima da média 
mundial de acesso à internet. A inclusão saltou dos $8 \%$ de domicílios com internet para $33 \%$ em nove anos e ocupou o $63^{\circ}$ lugar no mapeamento feito pela Fundação Getúlio Vargas (FGV) entre 154 países. A tecnologia trouxe novos formatos para vida cotidiana, mudando o comportamento de toda uma sociedade, influenciando na sua cultura, e esse avanço não para. Ele está acontecendo no momento em que este artigo é redigido e continua no momento em que você está lendo. Todos os dias nos deparamos com um mercado novo e é por esse motivo que este trabalho tem como intuito principal, discorrer sobre o infoproduto, respondendo o seguinte questionamento: Como o comportamento do consumidor evoluiu desde o boom da internet à oferta de infoprodutos? Para respondê-la, faz-se necessário analisar o comportamento do consumidor desde os anos 2000 até a era dos produtos digitais, a partir da definição de qual é o perfil do consumidor deste tipo de produto e apontar quais infoprodutos apareceram neste período.

A metodologia adotada será a pesquisa bibliográfica e a documental, com ênfase em uma análise qualitativa. A primeira é a revisão da literatura existente a respeito de um determinado assunto, e é o ponto de partida da grande maioria dos estudos. Ora, não há o que dizer sobre um assunto tão atual como é o mercado digital sem que antes se exponha o que outros pesquisadores já falaram sobre o tema.

Da mesma forma, a pesquisa documental é uma importante aliada, tendo em vista que muitas das informações sobre o produto digital e o comportamento do consumidor está em artigos de jornais, blogs, sites e outros documentos que não passaram por tratamento analítico.

\section{Metodologia}

Este trabalho tem por objetivo apontar o comportamento do consumidor de infoprodutos. Apesar de ser um assunto consideravelmente novo, tem sido cada vez mais estudado por sua relevância para a atualidade. Para tanto, adotou-se os métodos de pesquisa bibliográfica e documental, de caráter qualitativo, no qual, de acordo com Pereira, Shitsuka, Parreira e Shitsuka (2018), o pesquisador utiliza o processo indutivo para interpretar e analisar os dados coletados durante o estudo.

Sobre a pesquisa bibliográfica, Boccato (2006) destaca que busca-se resolver um problema, ou seja, uma hipótese, por meio de referenciais teóricos publicados sobre determinado assunto, de forma a contribuir com a ciência. Seguindo o mesmo entendimento, Pereira et. al. (2018) salienta que a leitura dos autores que servem de base para os estudos é importante para se aprofundar no tema e desenvolver habilidades e competências cognitivas.

Já a pesquisa documental é uma grande aliada para a pesquisa bibliográfica. Como o próprio nome sugere, a pesquisa documental consiste na análise de documentos que não receberam tratamento analítico, como por exemplo, dados de jornais, revistas, filmes, fotos, dentre outros. Ana e Lemos (2018) pontuam que esta técnica de coleta de dados "tem como finalidade identificar informações pontuais nos documentos a partir de questões ou hipóteses de interesse. Dentre as principais vantagens destacam-se por ser uma fonte estável e rica, dando maior estabilidade aos resultados".

\section{Referencial teórico}

\subsection{O consumidor até os anos 2000}

Carlucci (2020) se questiona: afinal, quem mudou com o passar dos tempos, foi o mercado ou o consumidor? Num breve resumo sobre seu pensamento, o autor expõe que o consumidor da década de 50 - pós-guerra, não tinha muitas ofertas, logo o que custava caro era atribuído a qualidade. Em 70, o consumidor começa a se importar mais com o valor dos produtos, não comprava logo de cara e é tido como mais exigente. Na década de 80 , o consumidor está mais consciente do mercado e busca comparar preço e qualidade. De 90 a 2000 o consumidor está mais informado e começa a buscar o melhor custo/benefício. 
Vieira (2018) afirma que o comportamento do consumidor está mudando em ritmo acelerado e as práticas de estudar esse comportamento evoluindo constantemente, isso graças ao avanço da tecnologia. A internet, o marketing móvel e as mídias sociais influenciam drasticamente o comportamento do consumidor do mundo moderno.

A considerar que consumíamos o que nos era ofertado em tempos mais remotos, atualmente ao consumidor é apresentada uma gama de produtos que o possibilita o poder de escolha. A mudança é, sob esse ponto de vista, concomitante consumidor e mercado. E é para se adaptar a esse novo mercado e conquistar o público-alvo, que o produto digital é segmentado.

Como uma forma de organização desse mercado, os termos convergência e conectividade aparecem com frequência. O Mapa da Inclusão Digital (Neri, 2012) conceitua que convergência significa a unificação de dispositivos de acesso, enquanto conectividade a multiplicação de lugares de acesso. A união dos dois promete a redução de custos e amplia as possibilidades da realização de atividades cotidianas.

\subsection{O boom da internet}

Na primeira década dos anos 2000, Magalhães (2013) pontua que foram feitas diversas pesquisas para traçar o perfil do novo consumidor, considerando o boom da internet naquele período e a notável mudança de comportamento do consumidor diante da novidade. $\mathrm{O}$ boom da internet é o nome dado ao momento em que a tecnologia tornou-se uma moeda supervalorizada nos países mais desenvolvidos do planeta. Melo Júnior (2007) descreve o estouro da bolha como um evento ocorrido no fim da década de 90, que se caracterizou pela supervalorização de empresas da internet chamadas até então de "empresas Ponto.com" e posterior queda de ações. Desde então, tecnologia não parou de crescer, influenciando o mundo e mudando culturas inteiras.

A diferença da primeira geração da web para a atual não aponta mudanças tecnológicas significativas, mas de comportamento. Na atual geração, consumidores participam do processo sobre o que lhes é ofertado na internet. Esse conceito é conhecido como Web 2.0 (Magalhães, 2013, p. 3).

Importante salientar que apesar de a internet ser um bem que mudou a vida em sociedade, influenciou comportamentos, mercado e culturas, ela ainda não é democraticamente acessível a todos. Ainda há muita disparidade entre países ricos e pobres. Dentro de um mesmo país, como no Brasil, ainda há pessoas sem acesso ao mundo digital ou com acesso precário.

Contudo, um dado interessante é que "a felicidade do brasileiro, dada sua inclusão digital, está acima da norma mundial" (Neri, 2012, p.16). A afirmativa é uma narração acerca do resultado do ranking da felicidade, que usou a mesma base de dados da pesquisa do Mapa da Inclusão Digital. Mas o autor deixa claro, em seguida, que a percepção está relacionada a renda, logo, não se pode afirmar que a internet traz felicidade. À época, a pesquisa mensurou que o Distrito Federal era a região com maior acesso a internet em casa, estando com a pontuação de 58\% de domicílios conectados. Enquanto isso, no outro extremo estava o Maranhão, com 10,98\%. Um dado interessante para o presente trabalho é que a capital mais jovem do país, Palmas-TO, aponta com a terceira entre as capitais com mais uso da internet no ranking de utilização respondendo ao questionário sobre o uso da internet nos últimos três meses.

\subsection{Inovação de Mercado}

O mercado digital surgiu para suprir uma necessidade das pessoas que estão cada vez mais conectadas em busca de satisfazer seus desejos. A Hotmart, uma plataforma especializada no mercado digital precursora e a mais tradicional no Brasil, explana que este é um grande ecossistema de pessoas entregando soluções a um clique de distância. Alexandre (2019) conta que a empresa aposta como principais áreas e tendências de mercado, o E-commerce, que em 2018 cresceu 12\% com relação a 2017 e fatura R\$53,2 bilhões; a Economia Compartilhada, que é vista como o futuro do mercado digital onde as pessoas procurarão uma forma de dividir bens, serviços e experiências, isso tudo com a interação entre pessoas proporcionada pelas 
redes sociais; o Marketing Mobile, que é o aproveitamento do marketing voltado para a plataforma de celulares; a Produção De Conteúdo para a web, que em constante crescimento traduz o desejo de empresas estarem presentes online; Os Produtos Digitais ou infoprodutos, objeto deste trabalho, que são materiais produzidos em formato digital como e-books, vídeos, aplicativos e sites e que veremos mais profundamente sobre o assunto mais a frente.

Machado (2018) reitera que para atender a uma necessidade de conhecimento do ser humano é que, com o advento dos avanços tecnológicos, surgiram também os produtos digitais, ou seja, os infoprodutos.

Kotler (2013) vai além e pontua que produto é tudo aquilo que pode ser oferecido a um mercado para satisfazer um desejo ou uma necessidade.

\section{O infoproduto}

O infoproduto é o produto digital. Diferente do tradicional, ele obedece a um formato próprio que possa ser comportado no mercado digital, ou seja, ele precisa estar na internet. Machado (2018) afirma que infoprodutos oferecem ao passo de um download acesso a recursos, serviços e conteúdos mais baratos financeiramente ou gratuitos. Pedro (2017) conclui que infoprodutos são materiais de informação criados e distribuídos, de forma paga ou gratuita, em formato digital. Já Antunes (2017) afirma que o único objetivo da criação dos infoprodutos é atrair os clientes.

São exemplos de infoprodutos: e-books (livros digitais), videoaulas, screencasts (vídeo a partir da tela do computador), audiobooks (livros narrados e compactados em formato MP3), podcasts (gravações de áudio similar a programas de rádio), membership (sites de conteúdo privado para membros), e-magazines (revistas eletrônicas), kits (produtos digitais de diversos formados) (Pedro, 2017).

Tex (2019) cita os checklists (documento passo a passo ensinado algo), aulas ao vivo, mentorias (acompanhamento de grupos em longo prazo), mastermind (encontros de profissionais de alto desempenho que almejam compartilhar e melhor seus resultados), consultoria (acompanhamento individual), desafios (dicas compartilhadas a um grupo de pessoas com metas para serem cumpridas).

Piccini (2020) ressalta que a questão é compreender como o infoproduto pode agregar valor a vida do ser humano: os infoprodutos servem para atender a uma necessidade da pessoa que o consome. Para quem produz o produto digital os atrativos principais são o baixo custo, a facilidade em começar o negócio e o lucro.

Ao falar sobre negócios rentáveis no mundo digital, a empreendedora Tex (2019) afirma que o conhecimento pode ser vendido no mercado digital e tem poder transformador na vida das pessoas e ao explicar o que difere o infoproduto de um produto comum, ela conceitua como "materiais que contêm um determinado conhecimento e que é entregue a alguém sem que aconteça uma transação física. Tudo ocorre online" (Tex, 2019, p.13).

Pode-se perceber que mesmo quando há uma troca física, em algum momento, o mercado aposta nas mídias digitais para vender seu produto, ter contato com o cliente, fazer o pós-venda... enfim, mesmo quando o processo for tradicional, o digital provavelmente estará presente.

\section{O Comportamento do Consumidor de Infoproduto}

Desde os anos 2000, passando pelo o boom da internet, na era da Web 2.0, o consumidor vem se tornando cada vez mais exigente e participante do processo. Ele começou estando mais informado nos anos 90 e a partir dos anos 2000, mais exigente. Se antigamente o consumidor estava preso a poucos canais de TV e rádio, estando mais propício a ser influenciado pelas grandes marcas e levado pelo pensamento em massa, a nova geração de consumidores - com infinitas opções de 
entretenimento, escolhem o que querem consumir. Este novo mundo online determina que o comportamento do consumidor moderno é o que vislumbra cada vez mais comprar com preços baixos e qualidade (Carlucci, 2020).

Tex (2019) aposta que há consumidores em toda a rede procurando por algo que atenda suas necessidades, por exemplo, ao incentivar a venda do produto digital, a autora considera que as pessoas na internet buscam aprender sobre aquilo. Quem sabe cozinhar, pode vender um curso online sobre como aprender a cozinhar; quem sabe outras línguas, pode vender um curso de línguas, e assim por diante. Sempre haverá alguém interessado no que você pode oferecer. Fato interessante é que a questão do nicho de mercado é favorável nesse processo, por exemplo, um e-book sobre comida vegana ou um checklist sobre como organizar melhor o seu tempo.

Tex (2019) explica que na internet, trabalhar com nichos é fundamental, pois são boas apostas de negócios no que diz respeito a fugir das grandes marcas que têm mais poder financeiro e driblar a concorrência. A autora esclarece que o nicho é diferente de segmento. Enquanto o último pode ser compreendido como algo maior, o nicho é uma parte do todo. Por exemplo: no segmento alimentação, a alimentação vegana é um nicho. No segmento esporte, o tênis de corrida é um nicho.

\section{Considerações Finais}

Ao observar esse comportamento do consumidor de infoproduto, pode-se dizer que todos que estão na rede podem ser considerados consumidores em potencial de um infoproduto. Ora, a rede está constantemente tentando influenciar quem faz parte dela. Digitais influencers é uma profissão, assim como criador de conteúdo. Muitas dessas pessoas nas redes têm nesse trabalho sua fonte de renda e ganham para influenciar pessoas a consumirem determinado tipo de serviço ou produto, físico ou digital. Mas quem de fato consome o infoproduto? Qualquer um que já tenha adquirido um produto ou serviço por meio online, sem contato ou presença física, pode ser considerado um consumidor de infoproduto. E o consumidor do infoproduto é o mesmo consumidor tradicional? Não. Com tudo o que foi colocado neste trabalho é possível afirmar que o consumidor do infoproduto tem um comportamento diferente do consumidor tradicional. Enquanto o primeiro está na rede em busca do melhor custo-benefício, é participante ativo do processo, pode ser o comprador de um produto e até vender outro - indicando o produto ou serviço utilizado, com o consumidor tradicional nada desse comportamento é visto. Este ainda prefere o método mais engessado do processo, sem falar da desconfiança. Ainda há consumidores que não confiam em comprar um produto sem tocá-lo para ter certeza de que é bom. Ainda há consumidores que preferem a ida à livraria, pegar no livro de papel, sentir suas páginas e o cheiro de novo, em vez de adquirir um e-book.

Portanto, conclui-se que o comportamento do consumidor de infoproduto é o perfil de quem está na rede - aquele que pesquisa, compara preços, exige qualidade, debate a qualidade do produto, cobra e paga (muitas vezes) por um produto ou serviço direcionado ao seu próprio perfil.

Importante ressaltar que mais estudos sobre essa temática se fazem necessários, visto que o assunto abordado é relativamente novo e o presente artigo aponta um caminho, mas não esgota todas as possibilidades que podem ser exploradas. Outras abordagens podem ser objeto de trabalhos futuros, tais como: $\mathrm{O}$ que faria um consumidor tradicional migrar para $\mathrm{o}$ mercado digital? Quais as vantagens e desvantagens dos mercados digitais para os consumidores?, dentre outras.

\section{Referências}

Alexandre, L. S. (2019). Mercado Digital: descubra o que é e as melhores áreas para começar. https://blog.hotmart.com/pt-br/mercado-digital

Ana, W. P. S. \& Lemos, G. C. (2018). Metodologia científica: a pesquisa qualitativa nas visões de Lüdke e André. Revista Eletrônica Científica Ensino Interdisciplinar, Mossoró, RN. 4(12), 531-541. http://periodicos.uern.br/index.php/RECEI/article/view/2870/1803

Antunes, E. M. (2017). Aplicação do Marketing Digital para Infoprodutos na área da Educação Física e do Esporte. http://repositorio.roca.utfpr.edu.br/jspui/bitstream/1/14299/1/CT_MBAGE_III_2018_04.pdf 
Research, Society and Development, v. 10, n. 3, e0310312874, 2021

(CC BY 4.0) | ISSN 2525-3409 | DOI: http://dx.doi.org/10.33448/rsd-v10i3.12874

Boccato, V. R. C. (2006). Metodologia da pesquisa bibliográfica na área odontológica e o artigo científico como forma de comunicação. Revista de Odontologia da Universidade de São Paulo, 18(3), 265-274.

Carlucci, C. (2020). Quem mudou: o mercado ou o consumidor? https://canaltech.com.br/mercado/Quem-mudou-o-mercado-ou-o-consumidor/

Kotler, P., \& Keller, K. L. (2013). Administração de marketing. (14a ed.) Prentice Hall.

Júnior, C. S. M. (2007). Web 2.0 e os Mashups: Reinventando a internet. Brasport.

Machado, C. H. (2018). Produtos digitais (infoprodutos): definição, processos criativos, mercado. https://riuni.unisul.br/bitstream/han dle/12345/5467/AD6_artigo_FINAL_CARLOSHMACHADO_CONCLU\%C3\%8DDO.pdf

Machuca, N. (2013). Manual de submissão: Revista de Administração Contemporânea. 16-40. http://www.anpad.org.br/diversos/p eriodicos/rac/rac_manual_submissao_2013.pdf

Magalhães, C. M., Araújo, C. G., Oliveira, E. T., \& Souza, H. L. (2013). O Boom da Internet e o Impacto na Relação entre Empresas e Consumidores. XVIII Congresso de Ciências da Comunicação na Região Sudeste. Bauru, SP, Brasil. http://portalintercom.org.br/anais/sudeste2013/resumos/R38-0315-1.pdf

Neri, M. C. (2012). Mapa da Inclusão Digital. Recuperado de https://bibliotecadigital.fgv.br/dspace/bitstream/handle/10438/20738/Sumario-Executivo-apada-Inclusao-Digital.pdf

Pedro, J. (2017). Aprenda o que são infoprodutos e conheça 8 formatos que você pode criar para trabalhar na internet! https://blog.hotmart.com/pt-br/tiposcriar-infoprodutos/

Pereira, A. S., Shitsuka, D. M., Parreira, F. J. \& Shitsuka, R. (2018). Metodologia da pesquisa científica. https://repositorio.ufsm.br/bitstream/handl e/1/15824/Lic_Computacao_Metodologia-Pesquisa-Cientifica.pdf?sequence=1.

Piccini, B. (2020). Infoprodutos: o que são e como criar um produto digital do zero. https://www.empreendedor-digital.com/infoprodutos

Tex, A. M., \& Larrossa, L. (2019). Desperte seu conhecimento milionário. Editora Gente.

Vieira, V. A. (2000). Comportamento do Consumidor. (6a ed.). Editora LTC. 